\title{
CAN DIFFICULT INTUBATION BE EASILY AND RAPIDLY PREDICTED?
}

\author{
Sarka Fritscherova ${ }^{\mathrm{a}}$, Milan Adamus ${ }^{\mathrm{a} *}$, Katerina Dostalovaa, Jirina Koutna ${ }^{\mathrm{a}}$, Lumir Hrabalek ${ }^{\mathrm{b}}$, \\ Jana Zapletalova ${ }^{\mathrm{c}, \mathrm{d}}$, Radovan Uvizl ${ }^{\mathrm{a}}$, Vladimir Janout ${ }^{\mathrm{e}}$
}

a Department of Anesthesiology, Resuscitation and Intensive Medicine, University Hospital Olomouc and Faculty of Medicine and Dentistry, Palacky University Olomouc, Czech Republic

${ }^{b}$ Department of Neurosurgery, University Hospital Olomouc and Faculty of Medicine and Dentistry, Palacky University Olomouc

c Department of Medical Biophysics, Faculty of Medicine and Dentistry, Palacky University Olomouc

d Department of Molecular and Translational Medicine, Faculty of Medicine and Dentistry Palacky University Olomouc

e Department of Preventive Medicine, Faculty of Medicine and Dentistry, Palacky University Olomouc

E-mail:milan.adamus@seznam.cz

Received: February 2, 2011; Accepted: May 2, 2011

Key words: Difficult tracheal intubation/Prediction/Inter-incisor gap/Thyromental distance/Temporomandibular joint movement

Aim. Failed endotracheal intubation and inadequate ventilation with subsequent insufficient oxygenation can result in serious complications potentially leading to permanent health damage. Difficult intubation may occur not only in patients with apparent pathologies in the orofacial region but also, unexpectedly, in those without abnormalities. This study aimed at finding anthropometric parameters that are easy to examine and that would aid in predicting difficult intubation.

Method. A case-control study was undertaken. Based on defined criteria, 15 parameters were examined in patients with unanticipated difficult intubation. The parameters included a previous history of difficult intubation, pathologies associated with difficult intubation, clinical symptoms of airway pathology, the Mallampati score, upper lip bite test, receding mandible, and cervical spine and temporomandibular joint movement. Thyromental, hyomental and sternomental distances and inter-incisor gap were measured. The methods were precisely defined and the measurements were carried out by a trained anesthesiologist. Statistical analysis was performed on data from 74 patients with difficult intubation and 74 control patients with easy intubation.

Results. Significant predictors of difficult intubation were inter-incisor gap (IIG), thyromental distance (TMD) and class 3 limited movement of the temporomandibular joint. The IIG and TMD cut-offs were set at $42 \mathrm{~mm}$ and 93 $\mathrm{mm}$, respectively.

Conclusion. The results will be used to confirm these predictors in an anesthesiology clinic along with the aid of the laryngoscopic findings to improve the prediction of unanticipated difficult intubation.

\section{INTRODUCTION}

Failed tracheal intubation with subsequent inability to maintain an open airway and adequate oxygenation is not a common complication but it is the most frequent cause of brain damage or death during anesthesia. The incidence of all types of difficulties related to intubation or secured airway is estimated to range from $1 \%$ to $3 \%$. Failed intubation accounts for 0.05-0.35\% (ref. ${ }^{1}$ ). Safe airway management is crucial in anesthesiology and resuscitation. It is an integral part of the anesthesia that is administered in all types of operations. Airway management, adequate ventilation and oxygenation are among the basic therapeutic procedures in resuscitation. Tracheal intubation is routinely performed by anesthesiologists.

The inability to control the airway and ventilate the patient effectively may result in serious complications, having immediate impact on the quality of life and potentially leading to the patient's death. The main problem is hypoxia resulting in damage to the CNS at various levels. The risk of injury to the airway is also not negligible.
Ultimately, these complications may influence both the professional career and private life of the anesthesiologist. Mistakes in the algorithm for unanticipated difficult intubation are mainly due to unpreparedness. These considerations formed the basis of this study aimed at finding parameters that are easy to examine and that could better predict difficult intubations.

\section{MATERIALS AND METHODS}

The goal was to define parameters that are easy to measure in anesthesiology clinic and that would help predict unanticipated difficult intubation.

A case-control study was selected as the most appropriate. At the outset, criteria for difficult intubation were precisely defined to create a patient group. The criteria for difficult intubation with the optimal position of the head (the so-called sniffing position), applying external pressure to the cricoid cartilage (Sellick's maneuver) and after calling in an experienced anesthesiologist are as follows: 
- the patient cannot be intubated despite more than three attempts at direct laryngoscopy or more than three attempts at tracheal tube insertion

- tracheal intubation attempts lasting more than ten minutes

- with direct laryngoscopy, only the epiglottis or root of the tongue is seen (Cook's modification ${ }^{2}$ of CormackLehane's classification ${ }^{3}$, grades 3A, 3B, 4 - see Table 1)

Table 1. Laryngoscopic view - Cook's modification ${ }^{2}$ of Cormack-Lehane's classification ${ }^{3}$.

\begin{tabular}{|c|l|}
\hline Grade & Laryngoscopic view \\
\hline 1 & $\begin{array}{l}\text { With direct laryngoscopy, the glottic opening } \\
\text { is clearly visualized. The posterior commissure } \\
\text { and the entire length of both vocal cords can } \\
\text { be seen. }\end{array}$ \\
\hline 2A & $\begin{array}{l}\text { With direct laryngoscopy, the glottic opening } \\
\text { is partly visualized. The posterior commissure } \\
\text { and parts of both vocal cords can be seen. }\end{array}$ \\
\hline 2B & $\begin{array}{l}\text { With direct laryngoscopy, the posterior com- } \\
\text { missure is visualized. The vocal cords cannot } \\
\text { be seen. }\end{array}$ \\
\hline 3A & $\begin{array}{l}\text { With direct laryngoscopy, only the epiglottis } \\
\text { is visualized. Epiglottis can be lifted using an } \\
\text { introducer or bougie. }\end{array}$ \\
\hline 3B & $\begin{array}{l}\text { With direct laryngoscopy, only the epiglottis is } \\
\text { visualized. Epiglottis cannot be lifted using an } \\
\text { introducer or bougie. }\end{array}$ \\
\hline 4 & $\begin{array}{l}\text { With direct laryngoscopy, only the root of the } \\
\text { tongue is visualized. }\end{array}$ \\
\hline
\end{tabular}

Based on the literature, the following 15 factors were selected for study in patients who are difficult to intubate: a previous history of difficult intubation (DI) $\left(\right.$ ref. $\left.^{4}\right)$, pathologies associated with difficult intubation ${ }^{4}$, clinical symptoms of airway pathology ${ }^{4}$, the Mallampati score ${ }^{3,5}$, upper lip bite test (ULBT) (ref. ${ }^{6,7}$ ), receding mandible ${ }^{8}$, hyomental distance (HMD) (ref. ${ }^{8}$ ), temporomandibular joint movement ${ }^{8}$, anterior or posterior flexion of the cervical spine ${ }^{8}$, horizontal length of the mandible (HLM) ( ref. $^{9}$ ), neck circumference, thyromental distance (TMD) (ref. ${ }^{3,10,11}$ ), sternomental distance (SMD) (ref. ${ }^{3,9,12}$ ), inter-incisor gap (IIG) (ref., ${ }^{3,4,8,12}$ ) - distance between the incisors with mouth fully open. Methods for measuring the individual parameters were precisely defined (see Table 2).

The study was approved by the University Hospital Olomouc ethics committee and carried out by the Department of Anesthesiology, Resuscitation and Intensive Medicine. Included were patients over 18 years of age undergoing surgery under general anesthesia with their airway secured by tracheal intubation in whom intubation was difficult, in accordance with the above criteria. Patients in whom difficult intubation could be anticipated were excluded from the study. The reasons for difficult intubation was varied. Congenital causes include cleft lip and/or palate, micrognathia, malposition or size of anterior teeth, congenital deformities of the facial skeleton as a part of congenital syndromes, and short thick neck. Inflammatory processes were para- and retropharyngeal abscesses, acute epiglottitis, temporomandibular joint inflammation, ankylosing spondylitis, ankylosis of the atlanto-occipital joint, or trismus, making direct laryngoscopy difficult. Difficult tracheal intubation may also result from trauma, such as facial bone fracture, soft tissue damage and hematoma. The most frequent endocrine causes are acromegaly or a goiter. Other causes include oral and neck cancer, previous radiotherapy of these regions, edema of the laryngeal soft tissues in an allergic reaction/anaphylactic shock. Patients with clear pathologies in the orofacial region were not included.

On the following day, all the parameters were recorded by an anesthesiologist trained in methods for measuring parameters of difficult intubation. After giving informed consent, patients in whom unanticipated difficult intubation occurred were asked about previous difficult intubation and potentially associated conditions. The anesthesiologist paid attention to clinical symptoms of airway pathology and the potential presence of a receding mandible. He assessed the Mallampati score, upper lip bite test, temporomandibular joint movement and cervical spine movement. With a ruler, he measured IIG, HMD, TMD and SMD. A measuring tape was used to measure neck circumference and HLM.

In the next phase of the study, each patient with difficult intubation was matched to a control, i.e. a patient with easy intubation and comparable gender, age, height and weight. The tolerance ranges were 10 years of age, $10 \mathrm{~cm}$ in height and $10 \mathrm{~kg}$ in weight. A total of 74 casecontrol pairs were created and compared.

The data were statistically analyzed using the SPSS 15.0 software (SPSS Inc., Chicago, USA). The categorical parameters were compared with Fisher's exact test. The quantitative data were analyzed using the Mann-Whitney U test and Student's t-test. Normality was assessed with the Shapiro-Wilk test. The cut-off values for non-metric parameters were determined by the ROC analysis. To define significant factors for predicting difficult intubation, logistic regression analysis was used. The tests were performed at a significance level of 0.05 .

\section{RESULTS}

Over a period of three years (2007-2010), a total of 98 patients were examined, in whom the above criteria for unanticipated difficult intubation were met as attempts were made to secure their airways with an endotracheal tube. Subsequently, patients with difficult intubation were matched with patients who also underwent surgery under general anesthesia with orotracheal intubation without difficulties. Twenty-four patients with difficult intubation were excluded since corresponding controls could not be found for them. Thus, a total of 74 pairs were created 
Table 2. Parameters for prediction of difficult intubation.

\begin{tabular}{|c|c|c|}
\hline Parameter & Methods & Ranges and units \\
\hline Previous history of DI & $\begin{array}{l}\text { Does the patient have a history of } \\
\text { difficult intubation? }\end{array}$ & yes - no \\
\hline Pathologies associated with DI & $\begin{array}{l}\text { Does the patient have a condition } \\
\text { commonly associated with difficult } \\
\text { intubation? }\end{array}$ & $\begin{array}{l}\text { specify } \\
\text { (ankylosing spondylitis, acromegaly, } \\
\text { etc.) }\end{array}$ \\
\hline Clinical symptoms & $\begin{array}{l}\text { hard to define - a feeling of a poten- } \\
\text { tial problem }\end{array}$ & yes - no \\
\hline Mallampati score & $\begin{array}{l}\text { full mouth opening } \\
\text { protrusion of the tongue }\end{array}$ & $\begin{array}{l}1=\text { the soft palate, uvula, pharynx } \\
\text { tonsils } \\
2=\text { the soft palate, uvula } \\
3=\text { the soft palate, base of the uvula } \\
4=\text { the soft palate only }\end{array}$ \\
\hline Upper lip bite test & $\begin{array}{l}\text { biting the upper lip with the lower } \\
\text { incisors }\end{array}$ & $\begin{array}{l}1=\text { the incisors in front of the lip } \\
2=\text { the lip partly visible } \\
3=\text { the lip visible }\end{array}$ \\
\hline Receding mandible & $\begin{array}{l}\text { a line drawn from the upper eye lid } \\
\text { to the maxilla }\end{array}$ & $\begin{array}{l}\text { yes - the chin behind the line } \\
\text { no - the chin in front of the line }\end{array}$ \\
\hline $\begin{array}{l}\text { Hyomental } \\
\text { distance (HMD) }\end{array}$ & $\begin{array}{l}\text { the body of the hyoid bone - the } \\
\text { mentum }\end{array}$ & $\mathrm{mm}$ \\
\hline TM joint movement & mouth opening + slux* & $\begin{array}{l}1=\mathrm{IIG}>50 \mathrm{~mm}+\operatorname{slux}>0 \\
2=\mathrm{IIG}<50 \mathrm{~mm}+\operatorname{slux}>0 \\
3=\mathrm{IIG}<50 \mathrm{~mm}+\operatorname{slux}<0\end{array}$ \\
\hline Anterior flexion of the C-spine & the goniometer head to the ear & anterior flexion in degrees \\
\hline $\begin{array}{l}\text { Posterior flexion of the } \\
\text { C-spine }\end{array}$ & $\begin{array}{l}1 \text { st arm in the long axis of the neck } \\
\text { above the ear } \\
2 \text { nd arm to the nasal wing }\end{array}$ & posterior flexion in degrees \\
\hline Mandibular length & $\begin{array}{l}\text { outer angle - the middle of the chin } \\
\text { (follow the shape of the mandible) }\end{array}$ & $\mathrm{cm}$ \\
\hline Neck circumference & $\begin{array}{l}\text { measured at the level of the cricoid, } \\
\text { perpendicular to the long axis of the } \\
\text { neck }\end{array}$ & $\mathrm{cm}$ \\
\hline Thyromental distance (TMD) & $\begin{array}{l}\text { the superior thyroid notch - the } \\
\text { lower edge of the middle of the chin }\end{array}$ & $\mathrm{cm}$ \\
\hline Sternomental distance (SMD) & $\begin{array}{l}\text { jugulum - the lower edge of the } \\
\text { middle of the chin }\end{array}$ & $\mathrm{cm}$ \\
\hline $\begin{array}{l}\text { Inter-incisor gap } \\
\text { (IIG) }\end{array}$ & between the incisors (gums) & $\mathrm{cm}$ \\
\hline
\end{tabular}

*slux- subluxation (maximal forward protrusion of the lower incisors beyond the upper incisors)

and statistically compared. (Table 3 ) shows no statistically significant difference between the two groups $(\mathrm{p}>0.05)$.

The categorical data are shown in (Table 4). There were significant differences in pathologies associated with difficult intubation, clinical symptoms of airway pathology, proportion of patients with class 3 or 4 Mallampati score, class 3 ULBT, the presence of a receding mandible and limited temporomandibular joint movement $(\mathrm{p}<$ 0.0001 ) between the case and control groups. The only statistically insignificant parameter was a previous history of difficult intubation. 
Table 3. Demographics of patients with difficult and easy intubation.

\begin{tabular}{|c|c|c|c|}
\hline & $\begin{array}{c}\text { Difficult } \\
(\mathrm{N}=74)\end{array}$ & $\begin{array}{c}\text { Easy } \\
(\mathrm{N}=74)\end{array}$ & $P$ \\
\hline Gender M/F & $35(47.3 \%) / 39(52.7 \%)$ & $35(47.3 \%) / 39(52.7 \%)$ & $1.000^{\mathrm{a}}$ \\
\hline Age $(\mathrm{yr})$ & $59.2 \pm 11.6^{2}$ & $59.9 \pm 10.6^{2}$ & $0.702^{\mathrm{b}}$ \\
\hline Weight $(\mathrm{kg})$ & $82.9 \pm 16.6^{2}$ & $82.5 \pm 16.8^{2}$ & $0.908^{\mathrm{b}}$ \\
\hline Height $(\mathrm{cm})$ & $169.3 \pm 9.1^{2}$ & $171.3 \pm 8.8^{2}$ & $0.170^{\mathrm{b}}$ \\
\hline BMI $\left.(\mathrm{kg.m})^{-2}\right)$ & $27.7(26.0-31.4)^{1}$ & $27.4(24.2-30.4)^{1}$ & $0.255^{\mathrm{c}}$ \\
\hline Obesity & $27(36.5 \%)$ & $23(31.1 \%)$ & $0.602^{\mathrm{a}}$ \\
\hline
\end{tabular}

${ }^{\text {a }}$ Fisher's exact test, ${ }^{\mathrm{b}}$ Student's t-test, ${ }^{\mathrm{c}}$ Mann-Whitney test

${ }^{1}$ median $\left(25^{\text {th }}-75^{\text {th }}\right.$ percentile $)$

${ }^{2}$ mean \pm SD

obesity $=$ BMI $>30 \mathrm{~kg} \cdot \mathrm{m}^{-2}$

Table 4. Categorical data (frequencies).

\begin{tabular}{|l|c|c|c|}
\hline & $\begin{array}{c}\text { Difficult } \\
(\mathrm{N}=74)\end{array}$ & $\begin{array}{c}\text { Easy } \\
(\mathrm{N}=74)\end{array}$ & $P$ \\
\hline Previous history of difficult intubation & $6(8.6 \%)$ & $1(1.4 \%)$ & $0.116^{\mathrm{a}}$ \\
\hline $\begin{array}{l}\text { Pathologies associated with difficult } \\
\text { intubation }\end{array}$ & $20(27.0 \%)$ & $1(1.4 \%)$ & $<\mathbf{0 . 0 0 0 1}^{\text {a }}$ \\
\hline Clinical symptoms & $28(37.8 \%)$ & $1(1.4 \%)$ & $<\mathbf{0 . 0 0 0 1}^{\text {a }}$ \\
\hline Mallampati score class 3 or 4 & $67(90.5 \%)$ & $28(37.8 \%)$ & $<\mathbf{0 . 0 0 0 1}^{\text {a }}$ \\
\hline ULBT class 3 & $25(33.8 \%)$ & $5(6.8 \%)$ & $\mathbf{0 . 0 0 0 1}^{\text {a }}$ \\
\hline Receding mandible & $29(39.2 \%)$ & $8(10.8 \%)$ & $\mathbf{0 . 0 0 0 1}^{\text {a }}$ \\
\hline TM joint movement class 3 & $35(47.3 \%)$ & $3(4.1 \%)$ & $<\mathbf{0 . 0 0 0 1}^{\text {a }}$ \\
\hline
\end{tabular}

${ }^{a}$ Fisher's exact test, ULBT = upper lip bite test, $\mathrm{TM}=$ temporomandibular

(Table 5) shows the descriptive characteristics of and posterior flexion of the cervical spine ( $\mathrm{p} 0.016$ and $\mathrm{p}$ the quantitative parameters. Statistically significant dif- $\quad=0.0002$, respectively $)$ HLM $(p=0.005)$ and SMD $(p=$ ferences were found for HMD $(p<0.0001)$, TMD $(p<\quad 0.005)$. No statistically significant difference was found $0.0001)$ and IIG ( $p<0.0001)$. Additionally, patients with for neck circumference.

difficult intubation were significantly different in anterior

Table 5. Quantitative parameters.

\begin{tabular}{|l|c|c|c|}
\hline & $\begin{array}{c}\text { Difficult } \\
(\mathrm{N}=74)\end{array}$ & $\begin{array}{c}\text { Easy } \\
(\mathrm{N}=74)\end{array}$ & $P$ \\
\hline HMD $(\mathrm{mm})$ & $55.0(50.0-65.0)^{1}$ & $60.0(60.0-70.0)^{1}$ & $\mathbf{0 . 0 0 0 1}^{\mathrm{a}}$ \\
\hline Anterior flexion of the C-spine $\left(^{\circ}\right)$ & $40.0(30.0-51.3)^{1}$ & $45.0(38.8-51.3)^{1}$ & $\mathbf{0 . 0 1 6}^{\mathrm{a}}$ \\
\hline Posterior flexion of the C-spine $\left(^{\circ}\right)$ & $30.0(25.0-40.0)^{1}$ & $40.0(35.0-50.0)^{1}$ & $\mathbf{0 . 0 0 0 2}^{\mathrm{a}}$ \\
\hline HLM $(\mathrm{cm})$ & $11.0(10.0-11.6)^{1}$ & $11.5(10.5-12.5)^{1}$ & $\mathbf{0 . 0 0 5}^{\mathrm{a}}$ \\
\hline Neck circumference $(\mathrm{cm})$ & $40.6 \pm 4.9^{2}$ & $40.0 \pm 4.4^{2}$ & $0.372^{\mathrm{b}}$ \\
\hline TMD $(\mathrm{mm})$ & $85.0(70.0-96.3)^{1}$ & $105.0(95.0-115.0)^{1}$ & $\mathbf{0 . 0 0 0 1}^{\mathrm{a}}$ \\
\hline SMD $(\mathrm{mm})$ & $155.0(130.0-166.3)^{1}$ & $165.0(145.0-175.0)^{1}$ & $\mathbf{0 . 0 0 5}^{\mathrm{a}}$ \\
\hline IIG $(\mathrm{mm})$ & $40.0(35.0-40.5)^{1}$ & $45.0(40.0-52.0)^{1}$ & $\mathbf{0 . 0 0 0 1}^{\mathrm{a}}$ \\
\hline
\end{tabular}

${ }^{\mathrm{a}}$ Mann-Whitney test, ${ }^{\mathrm{b}}$ Student's t-test

${ }^{1}$ median $\left(25^{\text {th }}-75^{\text {th }}\right.$ percentile $)$

${ }^{2}$ mean \pm SD

HMD $=$ hyomental distance, HLM = horizontal length of the mandible, TMD = thyromental distance, $\mathrm{SMD}=$ sternomental distance, IIG = inter-incisor gap 
For TMD and IIG, the ROC analysis was used to define cut-off values for predicting difficult intubation. For IIG, the optimal cut-off value was $42 \mathrm{~mm}$, sensitivity $79.7 \%$, specificity $71.6 \%$, positive predictive value $73.8 \%$ and negative predictive value $77.9 \%$. For TMD, the optimal cut-off value was $93 \mathrm{~mm}$, sensitivity $67.6 \%$, specificity $78.4 \%$, positive predictive value $75.8 \%$ and negative predictive value $70.7 \%$ (see Table 6 ).

Table 6. ROC analysis.

\begin{tabular}{|l|c|c|}
\hline & $\begin{array}{c}\text { IIG } \\
\text { cut-off=42 }\end{array}$ & $\begin{array}{c}\text { TMD } \\
\text { cut-off=93 }\end{array}$ \\
\hline AUC $(95 \% \mathrm{CI})$ & $0.824(0.759-0.889)$ & $0.789(0.718-0.860)$ \\
\hline Sensitivity & $0.797(0.688-0.882)$ & $0.676(0.557-0.780)$ \\
\hline Specificity & $0.716(0.599-0.815)$ & $0.784(0.673-0.871)$ \\
\hline Accuracy & $0.757(0.680-0.824)$ & $0.730(0.651-0.799)$ \\
\hline PPV & $0.738(0.627-0.830)$ & $0.758(0.636-0.855)$ \\
\hline NPV & $0.779(0.662-0.871)$ & $0.707(0.597-0.803)$ \\
\hline
\end{tabular}

AUC $=$ Area under the curve

PPV $=$ Positive predictive value

$\mathrm{NPV}=$ Negative predictive value

IIG $=$ Difficult intubation if IIG $\leq 42$

$\mathrm{TMD}=$ Difficult intubation if $\mathrm{TMD} \leq 93$

To select significant predictors for difficult intubation, logistic regression was used (see Table 7). Significant factors for predicting difficult intubation were clinical symptoms of airway pathology, with an odds ratio (OR) of 39.8 , class 3 limited movement of the temporomandibular joint (OR 10.2), neck circumference (OR 1.27), TMD (OR 0.894) and IIG (OR 0.819). Thus, the patient's clinical symptoms of airway pathology, suggesting difficult intubation to the anesthesiologist, increased the risk of difficult intubation 39.8-fold. Class 3 limited movement of the temporomandibular joint (mouth opening $<5 \mathrm{~cm}$ and inability to protrude the lower incisors beyond the upper incisors) meant a 10.2-fold higher risk of difficult intubation. If neck circumference was increased by 1 unit (cm), the likelihood of difficult intubation was 1.27 times higher. In contrast, a rise in TMD or IIG by 1 unit $(\mathrm{mm})$ decreased the chance of difficult intubation by factors of 0.894 and 0.819 , respectively.

Table 7. Logistic regression.

\begin{tabular}{|l|c|c|c|}
\hline & odds-ratio & $95 \% \mathrm{CI}$ & $P$ \\
\hline Clinical symptoms & 39.8 & $3.5-449.4$ & $\mathbf{0 . 0 0 3}$ \\
\hline TM joint movement=class 3 & 10.2 & $2.1-49.2$ & $\mathbf{0 . 0 0 4}$ \\
\hline Neck circumference $(\mathrm{cm})$ & 1.27 & $1.08-1.50$ & $\mathbf{0 . 0 0 4}$ \\
\hline TMD & 0.894 & $0.850-0.942$ & $<\mathbf{0 . 0 0 0 1}$ \\
\hline IIG & 0.819 & $0.741-0.905$ & $<\mathbf{0 . 0 0 0 1}$ \\
\hline
\end{tabular}

Nagelkerke R Square $=0.762$

\section{DISCUSSION}

Although a previous history of difficult intubation is considered a predictive factor it was statistically insignificant in this study. This may be explained by inadequate history taking. In only a few cases, was it possible to ascertain whether the patient had been under anesthesia and the types of anesthesia and airway management. Previous difficult intubation has a great importance ${ }^{4}$.
Similarly, pathologies associated with difficult intubation have a predictive value ${ }^{4}$. However, all patients with diseases or traumas causing deformities or greatly limiting movement in the head and neck region were excluded from the study.

Clinical symptoms of airway pathology, that is feelings the anesthesiologist has concerning the patient's potential intubation, are a very important predictive factor. Although this parameter cannot be quantified it should 
not be neglected in clinical practice ${ }^{4}$. Its predictive value is high but the ability to assess difficult intubation increases experience.

In common clinical practice, the Mallampati score is most widely used. However, this classification system is characterized by a high percentage of false-positive results. The actual predictive value is approximately $50 \%$ (ref. $^{3,5}$ ). In the literature, class 3 means up to 7.5-8 times higher risk for difficult intubation. But a 1992 German study showed that only $6.4 \%$ of class 4 patients were difficult to intubate ${ }^{3,5}$.

Although ULBT is a statistically significant test, in some cases such as elderly patients with artificial dentition, it may be more difficult to understand and perform. Similarly, patients with a severely receding mandible deserve more attention from the intubating anesthesiologist. This parameter is even more important when combined with other tests ${ }^{6,11}$.

Temporomandibular joint movement is assessed by a simple test consisting of two parts, full mouth opening and subluxation, i.e. forward protrusion of the lower incisors beyond the upper incisors. For patients, it is easier than ULBT. It showed to be an important predictor of difficult intubation in both this study and in the literature. This parameter is also a part of scoring systems such as the Arné or Wilson models ${ }^{4,8,12}$.

Movement of the cervical spine also has its role. For instance, patients with a history of ankylosing spondylitis are usually automatically assumed to be difficult to intubate. According to Wilson, the range of cervical spine movement defined as anterior + posterior flexion should be more than $90^{\circ}$ to predict easy intubation ${ }^{8}$. Interestingly, this range was not even achieved by some controls from the easy intubation group in the study. The range was $73.8-101.3^{\circ}$. Although we found the parameter to be statistically significant, its routine use in clinical practice is inhibited by both limited availability of equipment (a goniometer) and likely subjective error.

HLM is a metric parameter and if used on its own, it does not have much predictive value. Moreover, assessment using a measuring tape is usually influenced by the rater's error. Nevertheless, an HLM of at least $9 \mathrm{~cm}$ should guarantee easy intubation'.

As a single parameter, the neck circumference was not statistically significant, probably because the patients were matched by height and weight. However, logistic regression showed that an increase in one unit means that the likelihood of difficult intubation is 1.27 times higher. In most cases, greater neck circumference is associated with high body weight and some scoring models include weight as a risk factor for difficult intubation ${ }^{8,13-15}$. We did not confirm that. In this context, the assessment of some our results (e.g. the value of neck circumference in predicting DI) must be done with caution. In the logistic regression analysis, there are more variables which affect each other, neck circumference being only one of them. The regression model deals with the issue of probability and prediction of membership of a given parameter (here the neck circumference) into a group with easy or difficult intubation, respectively. On the contrary, the significance of the Student's t-test determines just the probability that the hypothesis of an identical neck circumference in easy and difficult intubation is rejected.

HMD is another metric parameter which was statistically significant. This is difficult to assess in overweight patients in whom the hyoid bone can hardly be identified. According to the literature, a distance of less than $4 \mathrm{~cm}$ is associated with difficult intubation.

SMD is a statistically significant metric parameter used in a large number of studies showing that a distance shorter than $13.5 \mathrm{~cm}$ is associated with difficult intubation $^{3,12}$.

TMD was defined by Patil as the distance from the thyroid notch to the mentum with the head extended. If TMD is shorter than $6 \mathrm{~cm}$ direct laryngoscopy usually cannot be performed. According to other authors, the distance is 6.5 or $7 \mathrm{~cm}^{3,10-12}$. In this study, the cut-off was defined as $9.3 \mathrm{~cm}$. Therefore, theoretically, a shorter distance may be associated with a more serious laryngoscopic picture and difficult intubation.

An IIG of at least $5 \mathrm{~cm}$ for tracheal intubation and $4 \mathrm{~cm}$ for inserting a laryngeal mask is another simple test with high predictive value ${ }^{3,12}$. In this study, the cut-off was set at $4.2 \mathrm{~cm}$, that is, patients with mouth opening less than $4.2 \mathrm{~cm}$ may experience difficulties with airway management.

Since the above parameters do not have high predictive value when used separately, various scoring systems have been described in the literature that increase the probability of difficult intubation predictions. An article by Naguib et al. ${ }^{16}$, published in Anesthesia \& Analgesia in 2006, evaluated three scoring models for assessing difficult intubation: the Wilson (weight, cervical spine movement, temporomandibular joint movement, receding mandible and buck teeth), Arné (previous difficult intubation, diseases associated with difficult intubation, clinical symptoms of airway pathology, temporomandibular joint movement, cervical spine movement and the Mallampati score) and Naguib (height, IIG, TMD and the Mallampati score). However, not even the combination of examination methods is reliable. The Wilson and Arné models have a sensitivity of approximately $50 \%$ but relatively low positive predictive value. The Naguib model is relatively sensitive $(81.4 \%)$ but its positive predictive value is even lower than that in the other two models (15.3\%) (ref. $\left.{ }^{16}\right)$.

\section{CONCLUSION}

Statistical analysis of the results yielded three parameters with high predictive value - the maximum distance between the incisors (gums), thyromental distance measured with the mouth closed and head extended, and decreased temporomandibular joint movement. The examination itself is neither time-consuming nor technically demanding. Therefore, the next steps will be to validate the factors, assess them in anesthesiology clinic and subsequently, evaluate the laryngoscopic findings in airway management of the assessed patients. 


\section{ACKNOWLEDGEMENTS}

The authors gratefully acknowledge financial support from the Czech Ministry of Health Internal Grant Agency project no. NS 9618-4/2008.

The authors express their sincere thanks to anesthesiologists and nurses from the Department of Anesthesiology, Resuscitation and Intensive Medicine, University Hospital Olomouc, for their help with data collection.

\section{REFERENCES}

1. Henderson JJ, Popat MT, Latto IP, Pearce AC. Difficult Airway Society Guidelines for Management of the Unanticipated Difficult Intubation. Anaesthesia 2004;59:675-94.

2. Cook TM. A New Practical Classification of Laryngeal View. Anaesthesia 2000;55:274-9.

3. Larsen R. Anestezie. $2^{\text {nd }}$ edition. Prague: Grada publishing; 2004. ISBN 80-247-0476-5.

4. Arné J, Descoins P, Fusciardi J, Ingrand P, Ferrier B, Boudigues D, Ariès J. Preoperative Assessment for Difficult Intubation in General and ENT Surgery: Predictive Value of Clinical Multivariate Risk Index. Br J Anaesth 1998;80:140-6.

5. Adamus M, Fritscherova S, Hrabalek L, Gabrhelik T, Zapletalova J, Janout V. Mallampati Test as a Predictor of Laryngoscopic view. Biomed Pap Med Fac Univ Palacky Olomouc Czech Repub 2010;154:339-44.

6. Eberhart LH, Arndt C, Cierpka T, Schwanekamp J, Wulf H, Putzke C. The Reliability and Validity of the Upper Lip Bite Test Compared with the Mallampati Classification to Predict Difficult Laryngoscopy: an External Prospective Evaluation. Anesth Analg 2005;101:284-9.
7. Shiga T, Wajima Z, Inouo T, Sakamoto A. Predicting Difficult Intubation in Apparently Normal Patients. Anesthesiology 2005;103:429-37.

8. Wilson ME, Spiegelhalter D, Robertson JA, Lesser P. Predicting Difficult Intubation. Br J Anaesth 1988;61:211-6.

9. Merah NA, Foulkes-Crabbe DJ, Kushimo OT. Prediction of Difficult Laryngoscopy in Population of Nigerian Obstetric Patients. West Afr J Med 2004;23:38-41.

10. Turkan S, Ates Y, Cuhruk H. Should We Reevaluate the Variables for Predicting the Difficult Airway in Anesthesiology? Anesth Analg 2002;94:1340-4.

11. Salimi A, Farzanegan B, Rastegarpour A. Comparison of the Upper Lip Bite Test with Measurement of Thyromental Distance for Prediction of Difficult Intubations. Acta Anaesthesiol Taiwan 2008;46:61-5.

12. Khan ZH, Mohammadi M, Rasouli MR. The Diagnostic Value of the Upper Lip Bite Test Combined with Sternomental Distance, Thyromental Distance, and Interincisor Distance for Prediction of Easy Laryngoscopy and Intubation: a Prospective Study. Anesth Analg 2009; 109:822-824.

13. Yildiz TS, Korkmaz F, Solak M. Prediction of Difficult Tracheal Intubation in Turkish Patients: a Multi-Center Methodological Study. Eur J Anesthesiol 2007;24:1034-40.

14. Juvine $P$, Lavaut E, Dupont H. Difficult Tracheal Intubation Is More Common in Obese Than in Lean Patients. Anest Analg 2003;97:595-600.

15. Eberhart LH, Arndt C, Aust HJ, Kranke P, Zoremba M, Morin A. A Simplified Risk Score to Predict Difficult Intubation: Development and Prospective Evaluation in 3763 Patients. Eur J Anaesthesiol 2010;27:935-40.

16. Naguib M, Scamman FL, O'Sullivan C, Aker J, Ross AF, Kosmach S, Ensor JE. Predictive Performance of Three Multivariate Difficult Tracheal Intubation Models: A Double-Blind, Case-Controlled Study. Anesth Analg 2006;102:818-24. 
